\title{
Effect of ascorbic acid on health and morphology of bovine preantral follicles during long-term culture
}

\author{
F. H. Thomas ${ }^{1}$, R. Leask ${ }^{2}$, V. Sršen ${ }^{3}$, S. C. Riley², N. Spears ${ }^{3}$ and \\ E. E. Telfer ${ }^{1,4 *}$ \\ ${ }^{1}$ Institute of Cell and Molecular Biology, The Darwin Building, University of Edinburgh, \\ King's Buildings, Mayfield Road, Edinburgh EH9 3JR, UK; ${ }^{2}$ Department of Reproductive and \\ Developmental Sciences, Obstetrics and Gynaecology Section, Centre for Reproductive \\ Biology, University of Edinburgh, Edinburgh, UK; and ${ }^{3}$ Department of Biomedical Sciences, \\ Hugh Robson Building, University of Edinburgh, Edinburgh, UK
}

During ovarian folliculogenesis, ascorbic acid may be involved in collagen biosynthesis, steroidogenesis and apoptosis. The aims of this study were to determine the effects of ascorbic acid on bovine follicle development in vitro. Preantral follicles were cultured for 12 days in serum-free medium containing ascorbic acid $\left(50 \mu \mathrm{g} \mathrm{ml}^{-1}\right)$. Half of the medium was replaced every 2 days, and conditioned medium was analysed for oestradiol and matrix metalloproteinase 2 (MMP-2) and MMP-9 secretion. On day 12 , cell death was assessed by TdTmediated dUTP-biotin nick end labelling (TUNEL). In the absence of serum, there was significant $(P<0.05)$ follicle growth and oestradiol secretion over the 12 day culture period. Ascorbic acid had no effect on these parameters.
The addition of serum from day 0 stimulated follicle growth $(P<0.05)$, but compromised follicle integrity. By day 12 of culture, a higher proportion of follicles remained intact in the presence of ascorbic acid in serum-free conditions $(P<0.05)$, and significantly $(P<0.01)$ less granulosa and theca cell death was observed in these follicles than in control follicles. Moreover, ascorbic acid significantly $(P<0.05)$ increased production of MMP-9, an enzyme involved in basement membrane remodelling. In conclusion, this culture system was capable of supporting follicle differentiation over the $\mathbf{1 2}$ day culture period. Furthermore, ascorbic acid maintains bovine follicle health and basement membrane remodelling in vitro.

\section{Introduction}

Techniques that have been developed for isolating and culturing preantral follicles from a range of rodents have produced developmentally competent oocytes and viable offspring (Eppig and Schroeder, 1989; Roy and Greenwald, 1989; Torrance et al., 1989; Spears et al., 1994; Cortvrindt et al., 1996). The limited success of these rodent culture systems has resulted in attempts to develop similar methods that can be applied to humans (Abir et al., 1997; Wright et al., 1999) and domestic species (reviews: Telfer et al., 2000; Van den Hurk et al., 2000).

For livestock production, the culture of small oocytes could potentially provide a large population of female germ cells. Advances have been made in transferring aspects of the rodent systems to the development of pig follicle systems in vitro (Hirao et al., 1994; Wu et al., 2001). However, less densely packed follicles, more fibrous stromal tissue, larger follicles and slow follicular growth have all played a role in delaying a successful system for isolation and culture of bovine preantral follicles.

*Correspondence

Email: Evelyn.Telfer@ed.ac.uk
Complete growth of bovine preantral follicles in vitro is ambitious as preantral development takes 4-5 months; therefore, prolonged culture is necessary if developmentally competent oocytes are to be obtained. In addition, as the follicles increase in size, problems of nutrient restriction and insufficient gas and waste exchange may arise. In previous studies that used bovine preantral follicles, culture was terminated long before the preovulatory stage (Figueiredo et al., 1995; Hulshof et al., 1995; Ralph et al., 1995; Gutierrez et al., 2000; Saha et al., 2000). Nevertheless, preantral follicles from sheep and cattle have been grown to the antral stage of development in vitro (Cecconi et al., 1999; Gutierrez et al., 2000; McCaffery et al., 2000), indicating that follicle differentiation can be achieved under culture conditions. However, follicle culture systems for domestic ruminants have been unsuccessful in obtaining oocytes capable of undergoing meiotic maturation.

McCaffery et al. (2000) identified markers of follicle health using a serum-free culture system for bovine preantral follicles. The present study aims to determine further optimum conditions for the support of oocyte growth and granulosa cell differentiation during the early stages of development.

Ascorbic acid, a dietary requirement for primates and a 
few other mammals, has been implicated in several processes associated with follicular and luteal development. It is widely distributed in animal tissues, and the highest concentrations are found in the pituitary, adrenal gland and gonads (Luck et al., 1995). Ascorbic acid accumulates in granulosa cells, theca interna, luteal cells and in oocytes (Kramer et al., 1933; Hoch-Ligeti and Bourne, 1948; Deane, 1952). Acting as an antioxidant, ascorbic acid has been implicated in the processes of hormone secretion, gonadal tissue remodelling and apoptosis (Luck et al., 1995).

Adequate turnover of components of the extracellular matrix of the follicle is essential for normal follicle growth, follicle repair after ovulation (Himeno et al., 1984) and subsequent development of the corpus luteum (Luck and Zhao, 1993). In species that have large follicles, such as humans and cattle, there is a high demand for collagen IV (a major constituent of the basement membrane). Ascorbic acid has been implicated in the biosynthesis of collagen, both at the gene level (Padh, 1991) and during protein synthesis (Pinnell, 1985; Hulmes, 1992). The enzymes involved in the turnover of collagen during follicle growth are the matrix metalloproteinases (MMPs), which are regulated by their endogenous tissue inhibitors of metalloproteinases (TIMPs). A serum-free culture system for bovine preantral follicles was used to show that MMP and TIMP activities are secreted in vitro, and that MMP-9, TIMP1 and TIMP-2 are markers of follicle health (McCaffery et al., 2000). Ascorbic acid may act to regulate these factors (Pfeffer et al., 1998; Murray et al., 2001).

The presence of high concentrations of ascorbic acid in endocrine tissues is thought to be important for the production of steroid hormones (Tsuji et al., 1989). In cows, concentrations of ascorbic acid in follicular fluid tend to be higher during the early part of the oestrous cycle (days 1-10 after ovulation) (Wise, 1987). This sequestration of ascorbic acid may occur to allow rapid expansion of the follicle or to facilitate post-ovulatory steroidogenesis (Luck et al., 1995). However, Sanyal and Datta (1979) reported that ascorbic acid at high concentrations inhibits steroidogenesis. Any effect of ascorbic acid on hormone synthesis during early follicular development remains to be clarified.

The role of ascorbic acid as a free radical scavenger is well understood. It is thought that follicular atresia is initiated as a consequence of inadequate protection of maturing granulosa cells from the damaging effects of reactive oxygen species (Tilly and Tilly, 1995). Oxidants induce apoptosis in cultured granulosa cells, and the addition of FSH or antioxidants, such as ascorbic acid, inhibit this response (Tilly and Tilly, 1995). In addition to follicular atresia, ascorbic acid deficiency causes premature resumption of meiosis and oocyte destruction (Kramer et al., 1933).

The aim of the present study was to use a serum-free culture system (McCaffery et al., 2000) to investigate the effects of ascorbic acid on bovine preantral and early antral follicle development in vitro. Follicle growth and integrity of the basement membrane were assessed during the culture period, and the effect of ascorbic acid on MMP production, oestradiol secretion and follicular cell death were investigated.

\section{Materials and Methods}

\section{Isolation of preantral follicles}

Bovine ovaries from random stages of the oestrous cycle were obtained from an abattoir and transported at $25^{\circ} \mathrm{C}$. In a laminar flow hood, ovaries were rinsed with $70 \%$ alcohol, and thin slices of ovarian cortex were taken using a scalpel and placed in dissection medium (Leibovitz's medium; GIBCO BRL, Life Technologies Ltd, Paisley) supplemented with sodium pyruvate $\left(2 \mathrm{mmol} \mathrm{I}^{-1}\right)$, glutamine $\left(2 \mathrm{mmol} \mathrm{I}^{-1}\right)$, BSA (Fraction V; $\left.3 \mathrm{mg} \mathrm{ml}^{-1}\right)$, penicillin $\mathrm{G}\left(75 \mu \mathrm{g} \mathrm{ml}^{-1}\right)$ and streptomycin $\left(50 \mu \mathrm{g} \mathrm{ml}^{-1}\right)$. All chemicals were obtained from Sigma Chemicals (Poole) unless otherwise stated. Preantral follicles $(146.02 \pm 1.71 \mu \mathrm{m})$ were isolated from the cortical slices under a dissecting microscope using 25-G needles. Approximately 15-30 follicles were isolated on each day of culture. Follicles with an intact basement membrane and an even distribution of granulosa and theca layers were selected for culture.

\section{Culture of preantral follicles}

For the control group, preantral follicles $(n=88)$ were cultured individually for 12 days in 96-well plates (Bibby Sterilin Ltd, Stone, Staffs) in $250 \mu$ l culture medium (McCoy's 5a medium with bicarbonate (Sigma)) supplemented with Hepes $\left(20.0 \mathrm{mmol}^{-1}\right)$, BSA $(0.1 \%)$, L-glutamine (3.0 mmol $\left.\mathrm{I}^{-1}\right)$, penicillin (100.0 iu $\left.\mathrm{ml}^{-1}\right)$, streptomycin $\left(0.1 \mathrm{mg} \mathrm{m}^{-1}\right)$, transferrin $\left(2.5 \mu \mathrm{g} \mathrm{ml}^{-1}\right)$, selenium (4.0 $\mathrm{ng}$ $\left.\mathrm{ml}^{-1}\right)$, androstenedione $\left(10^{-7} \mathrm{~mol} \mathrm{I}^{-1}\right)$ and insulin (10.0 ng $\left.\mathrm{ml}^{-1}\right)$. For the first treatment group $(n=82), 50 \mu \mathrm{g}$ L-ascorbic acid sodium salt $\mathrm{ml}^{-1}$ was added to the control medium and follicles were cultured for 12 days. The effect of fetal bovine serum (FBS, 10\%) on follicles from day 6 of culture onwards was also investigated with the addition of FBS to follicles in either ascorbic acid-treated $(n=33)$ or control $(n=33)$ groups. In addition, FBS was added to control $(n=20)$ or ascorbic acid-treated medium $(n=20)$ on day 0 and follicles were cultured for 10 days. Plates were incubated for 10 or 12 days in a sterile humidified atmosphere of air with $5 \% \mathrm{CO}_{2}$ at $37^{\circ} \mathrm{C}$. Each set of cultures $(n=12)$ was performed under identical conditions. Follicle diameters were measured under a dissection microscope at 2 day intervals, and follicles that maintained their threedimensional morphology were defined as intact. Half of the medium was replaced every second day, and this conditioned medium was stored at $-20^{\circ} \mathrm{C}$ for subsequent MMP analysis, or for analysis of oestradiol content.

\section{Detection of cell death in follicle whole mounts by TUNEL (TdT-mediated dUTP-biotin nick end labelling)}

At the end of the 12 day culture period, follicles were transferred to 24-well culture plates (Corning Costar) and 
then washed $\left(10 \mathrm{~min}, \mathrm{PBS}, 37^{\circ} \mathrm{C}\right)$. Cultured follicles $(n=35)$ and freshly isolated follicles (negative controls: $n=8$ ) were permeabilized and prefixed $(40 \mathrm{~min} ; 0.5 \%(\mathrm{v} / \mathrm{v})$ Triton$\mathrm{X} 100,0.25 \%(\mathrm{w} / \mathrm{v})$ paraformaldehyde in PBS at $\left.37^{\circ} \mathrm{C}\right)$, and then fixed (30 min; 4\% (w/v) paraformaldehyde in PBS at room temperature), washed in PBS $(2 \times 10 \mathrm{~min})$ and stored $\left(0.02 \%(\mathrm{w} / \mathrm{v}) \mathrm{NaN}_{3}\right.$ in PBS, $\left.4^{\circ} \mathrm{C}\right)$. Follicles were washed and equilibrated to room temperature with PBS (20 min; $2 \times 10$ min). Samples were then incubated with proteinase $K$ (Roche Diagnostics) (40 min, $17.1 \mu \mathrm{g} \mathrm{ml} \mathrm{m}^{-1}$ in PBS, $37^{\circ} \mathrm{C}$ ), refixed at room temperature $(20 \mathrm{~min}, 3 \%(\mathrm{w} / \mathrm{v})$ paraformaldehyde in PBS) and washed (10 min, 0.01\% (v/v) Triton-X100 in PBS; $2 \times 10$ min PBS). A preincubation with TdT buffer $(10 \mathrm{~min}, 30 \mathrm{mmol}$ Tris- $\mathrm{HCl} \mathrm{I-1}, \mathrm{pH} 7.2$, 140 mmol sodium cacodylate $\mathrm{I}^{-1}, 1 \mathrm{mmol}$ cobalt chloride $\mathrm{I}^{-1}$ ) was carried out before incubation with TUNEL reaction mixture $\left(2.5 \mathrm{~h}, 37^{\circ} \mathrm{C}\right.$ in the dark) from an in situ cell death detection kit, Fluorescein (Roche), which was prepared according to the manufacturer's instructions. Still in the dark, follicles were washed in PBS $(2 \times 10 \mathrm{~min})$ and incubated with propidium iodide $\left(1 \mathrm{~h}, 2.5 \mu \mathrm{g} \mathrm{m} \mathrm{m}^{-1}\right.$, room temperature) in bovine pancreatic RNase A (Roche). Samples were washed (20 min, 0.01\% (v/v) Triton-X100 in PBS; $2 \times 10 \mathrm{~min}$ PBS) and equilibrated in 50\% Vectashield (Vector Laboratories Ltd, Southgate) overnight at $4^{\circ} \mathrm{C}$. Follicles were mounted in $100 \%$ Vectashield on concave microscope slides and stored at $4^{\circ} \mathrm{C}$ in the dark. Follicle sections were analysed for fluorescein dUTP incorporation using the Leica TCSNT confocal system (Leica Microsystems, Milton Keynes). A single scan was taken through the centre of each follicle, as determined by central positioning of the propidium iodide stained germinal vesicle in the oocyte, using a $\times 63$ water corrected PLAPO lens. If the germinal vesicle was not detected, the largest cross-section of the follicle was used for analysis. Simultaneous scans at $488 \mathrm{~nm}$ (the green channel that shows any TUNEL labelled DNA) and $568 \mathrm{~nm}$ (the red channel that shows propidium iodide stained nuclear material) were taken. The number of TUNEL-labelled cells (granulosa and theca) and the number of propidium iodide stained cells in each middle section were counted. Owing to substantial loss of theca cells in groups treated with serum, the effect of ascorbic acid on theca cell death was analysed in the serum-free groups only.

\section{Detection of MMP-2 and MMP-9 in culture medium}

MMP-2 and MMP-9 activities were detected in culture medium by gelatin zymography as described by Riley et al. (1999). In brief, $100 \mu \mathrm{l}$ samples of serum-free culture medium from individual follicles (from five independent cultures carried out under identical conditions) on day 8 of culture $(n=24)$ were dialysed against distilled $\mathrm{H}_{2} \mathrm{O}$ in small 'tube-o-dialyser' dialysis tubes with a 15 kDa cut-off (Chemicon International, London) before being lyophilized and reconstituted in $7.5 \mu$ of $0.1 \%(w / v)$ SDS in $\mathrm{H}_{2} \mathrm{O}$. Samples were separated by SDS-PAGE using $7.5 \%$ gels containing
$1 \mathrm{mg}$ gelatin $\mathrm{ml}^{-1}$ on a minigel apparatus (BioRad, Hemel Hempstead). Gels were washed $(2 \times 15 \mathrm{~min}, 2.5 \%(\mathrm{v} / \mathrm{v})$ Triton-X100; $2 \times 2$ min TBS $\times 10$ ) and then incubated overnight at $37^{\circ} \mathrm{C}$ in digestion buffer $\left(50 \mathrm{mmol}\right.$ Tris $\mathrm{I}^{-1} ; 0.2$ mol $\mathrm{NaCl} \mathrm{I}^{-1} ; 5$ mmol $\mathrm{CaCl}_{2} \mathrm{I}^{-1}, 1 \mu \mathrm{mol} \mathrm{ZnCl}_{2} \mathrm{I}^{-1} ; 0.02 \%$ $(\mathrm{v} / \mathrm{v})$ Brij-35). Gels were stained for $3 \mathrm{~h}$ at $23^{\circ} \mathrm{C}(0.5 \%(\mathrm{w} / \mathrm{v})$ Coomassie blue R250 in 30\% methanol:10\% (v/v) glacial acetic acid in $\mathrm{H}_{2} \mathrm{O}$ ) and then destained (staining solution with Coomassie blue omitted). This revealed clear bands where the gelatin had been degraded by gelatinase activity. MMP-2 and MMP-9 were identified by comparison with molecular weight markers and control standards of human amniotic fluid collected during labour at term (Riley et al., 1999). MMP activities as detected by zymography were measured by transmission densitometry (G-700 Densitometer; BioRad). Relative intensities were derived from zymogram gels by comparison with parallel background readings of equal area and calculated using dedicated software (Quantity One; BioRad). Densitometric readings were compared only with another gel examined under precisely the same conditions (that is, the same electrophoresis run and identical buffers, stains and incubation periods).

\section{Detection of oestradiol in culture medium}

Concentrations of oestradiol in unextracted serum-free culture media $(n=87)$ were determined by radioimmunoassay as described by Webb et al. (1985). The sensitivity of the assay was $36 \mathrm{pg} \mathrm{ml}^{-1}$. The intra- and interassay coefficients of variation were 4.0 and $4.8 \%$, respectively.

\section{Statistical analyses}

Mean percentage increases in follicle diameter in the six experimental groups on day 8 , and the four experimental groups on day 12 were compared using one-way ANOVA followed by $t$ tests to allow for individual comparisons among groups. Within each group, correlations were obtained between percentage increase in follicle diameter and the percentage of follicles that remained intact during culture. In addition, the proportion of follicles remaining intact on every second day of culture was compared using a 2-proportions test. Follicles cultured for 12 days were assessed for granulosa and theca cell death by TUNEL. The percentage of labelled granulosa cells was compared among the four groups by ANOVA. In addition, the number of labelled granulosa cells as a proportion of the total number of cells in each treatment group was compared using chi-squared analysis. The effect of ascorbic acid on theca cell death was analysed in the serum-free groups using a 2-sample $t$ test. Oestradiol secretion was measured in serum-free control and ascorbic acid-treated follicles, and values were compared using ANOVA and subsequent 2 -sample $t$ tests. The MMP densitometry data were analysed using a 2 -sample $t$ test. 
(a)
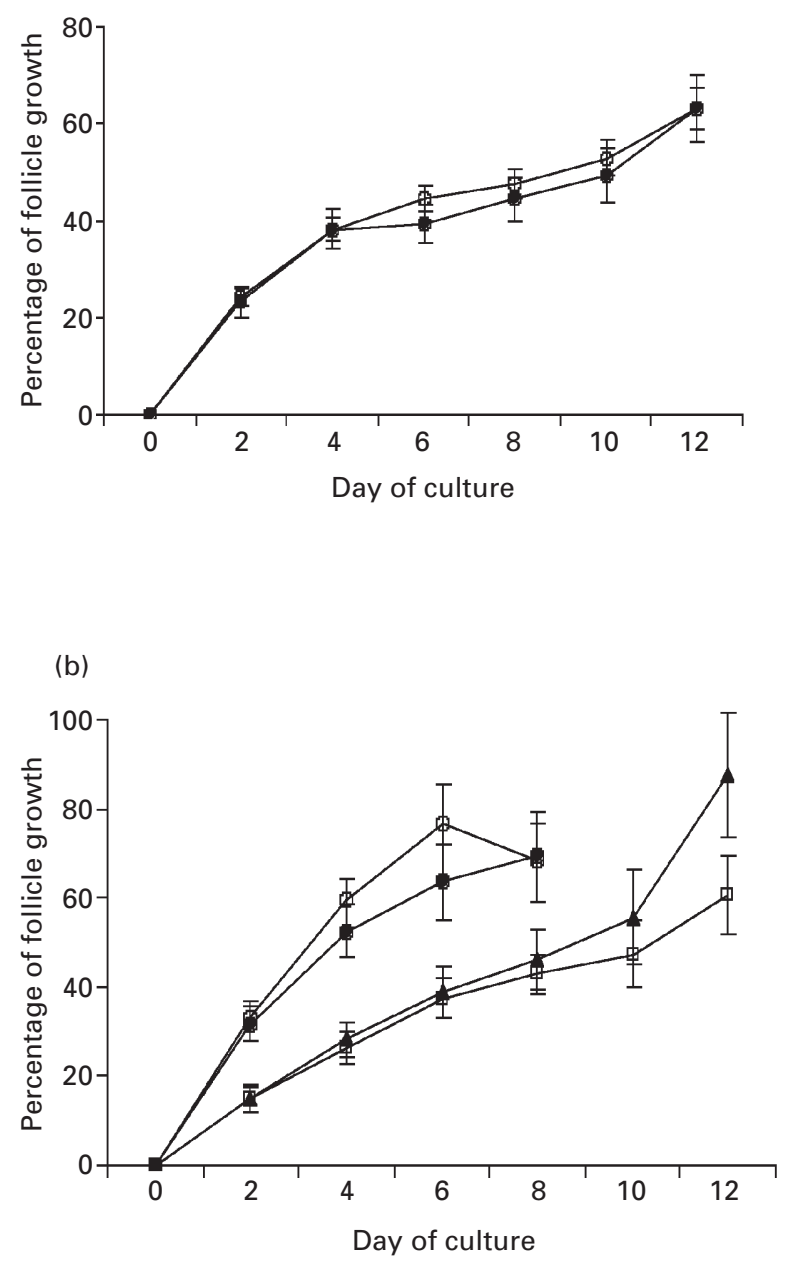

Fig. 1. (a) The effect of ascorbic acid on bovine follicle growth. Ascorbic acid $(\bigcirc ; n=82)$ and control $(\bullet ; n=88)$. Values are mean \pm SEM. (b) The effect of serum on bovine follicle growth. Fetal bovine serum (FBS) was added on day $0(-n=20)$, FBS was added on day $6(\square ; n=33)$, ascorbic acid with FBS was added on day $0(O ; n=20)$ and ascorbic acid with FBS was added on day 6 $(\mathbf{\Lambda} ; n=33)$. Values are mean \pm SEM. $n$ represents the number of follicles in each treatment group at the beginning of culture.

\section{Results}

\section{Follicle growth}

Follicles were cultured for 12 days in serum-free medium in the presence $(n=82)$ or absence $(n=88)$ of ascorbic acid. In addition, FBS was added to follicles cultured in the presence or absence of ascorbic acid on day $0(n=40)$ or day $6(n=66)$ of culture. There was significant follicle growth in all treatment groups $(P<0.01)$ (Fig. 1). Follicles cultured in medium containing serum from day 0 were terminated at day 10 because of an increased incidence of follicle rupture. As a result of follicle loss in these groups, only measurements up to day 8 of culture were used for measurement of follicle growth (Fig. 1b). On day 8 there (a)

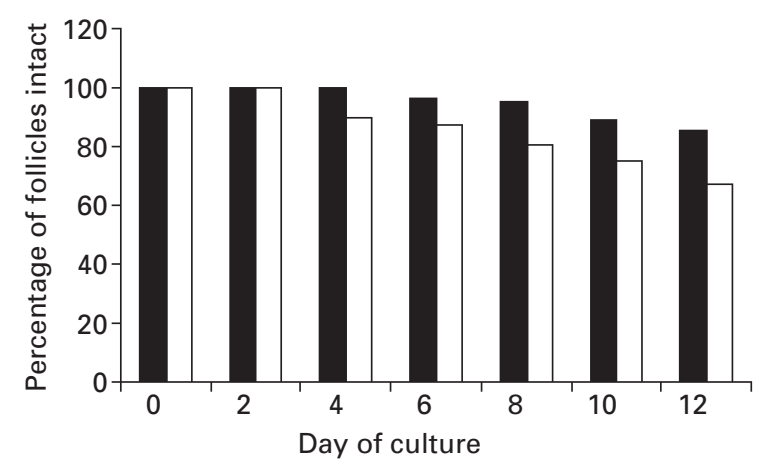

(b)

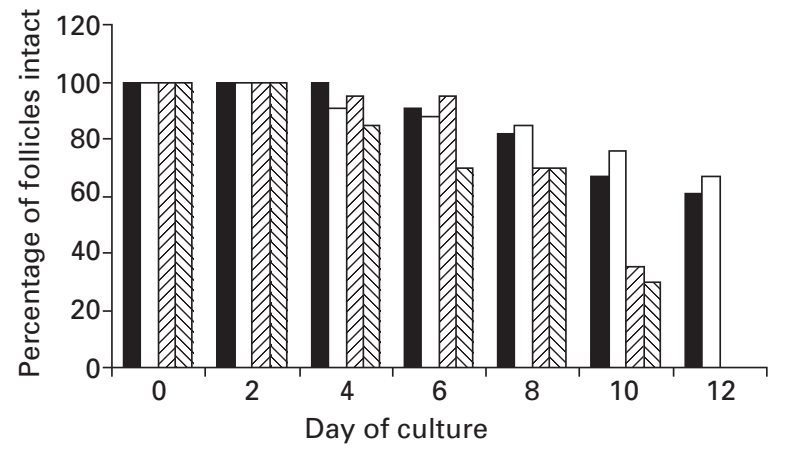

Fig. 2. (a) The effect of ascorbic acid on the integrity of bovine follicles. Ascorbic acid ( $\square ; n=82$ ) and control $(\square ; n=88)$. (b) The effect of serum on the integrity of bovine follicles. Ascorbic acid with fetal bovine serum (FBS) was added on day $6(\boldsymbol{\square} ; n=33)$, FBS was added on day 6 ( $\square ; n=33$ ), ascorbic acid with FBS was added

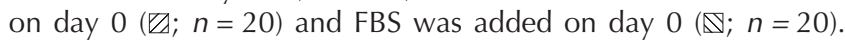
$n$ represents the number of follicles in each treatment group at the beginning of culture.

was a significant difference in the percentage of follicle growth among all treatment groups $(P<0.05)$. Follicles cultured in serum (with and without ascorbic acid) from day 1 of culture had a higher percentage increase in follicle diameter by day 8 than follicles cultured in serum-free medium $(P<0.05)$. However, serum alone did not significantly increase the percentage increase in follicle diameter compared with follicles treated with ascorbic acid in serumfree medium. When FBS was added to follicles on day 6, there was no difference in percentage follicle growth by day 12 compared with control or ascorbic acid-treated follicles in the absence of serum.

\section{Follicle integrity}

There was a negative correlation $(P<0.05)$ between percentage follicle growth (as described above) and the percentage of follicles remaining intact (that is, maintaining 
Table 1. Effect of ascorbic acid and serum on the percentage cell death in bovine granulosa and theca cells on day 12 of culture

\begin{tabular}{lcc}
\hline Treatment & $\begin{array}{c}\text { TUNEL-labelled } \\
\text { granulosa cells } \\
\text { (mean \% } \pm \text { SEM) }\end{array}$ & $\begin{array}{c}\text { TUNEL-labelled } \\
\text { theca cells } \\
\text { (mean \% } \pm \text { SEM) }\end{array}$ \\
\hline Day 0 & $0 \pm 0^{\mathrm{a}}$ & $0 \pm 0^{\mathrm{a}}$ \\
Control (day 12) & $6.44 \pm 3.23^{\mathrm{b}}$ & $48.68 \pm 4.42^{\mathrm{b}}$ \\
Ascorbic acid (day 12) & $0 \pm 0^{\mathrm{a}}$ & $20.28 \pm 1.93^{\mathrm{ab}}$ \\
Fetal bovine serum (day 12) & $12.43 \pm 4.13^{\mathrm{b}}$ & - \\
Ascorbic acid + fetal bovine serum (day 12) & $0 \pm 0^{\mathrm{a}}$ & - \\
\hline
\end{tabular}

asignificantly less cell death than the control $(P<0.001)$.

bSignificantly more cell death than at day $0(P<0.001)$.

(a) (i)

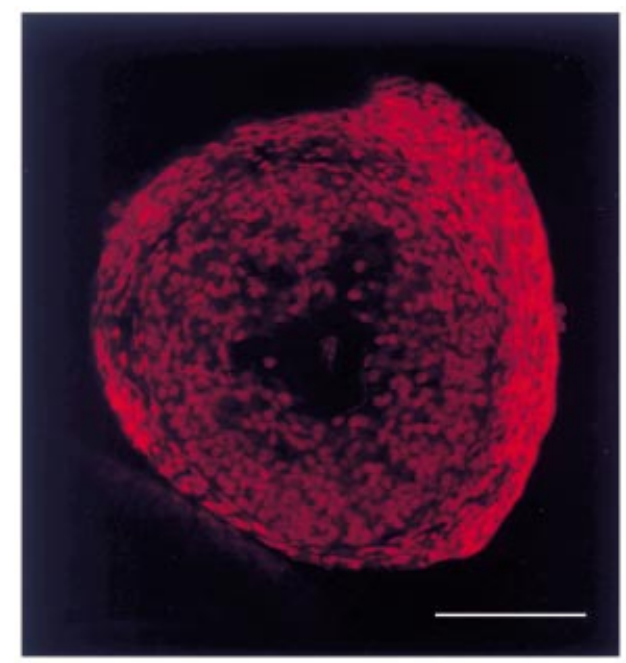

(b) (i)

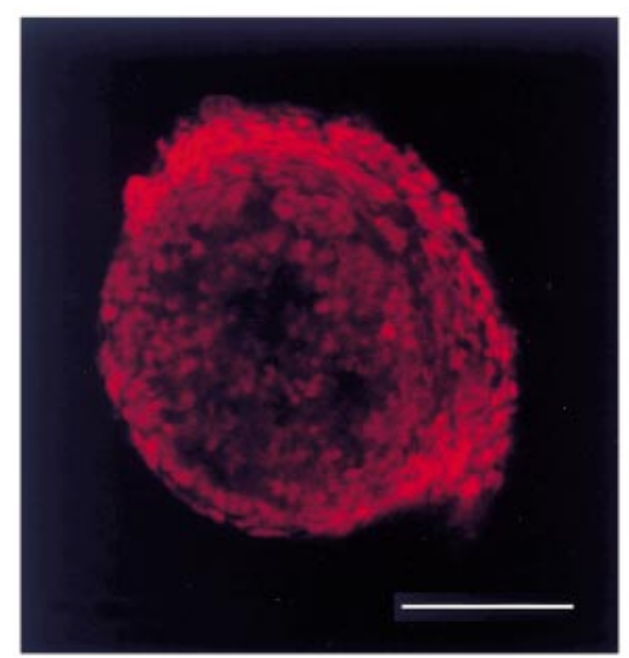

(ii)

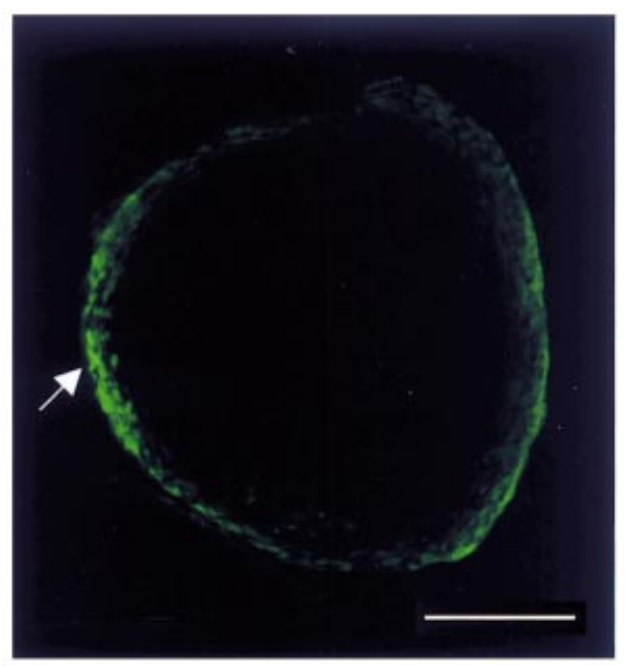

(ii)

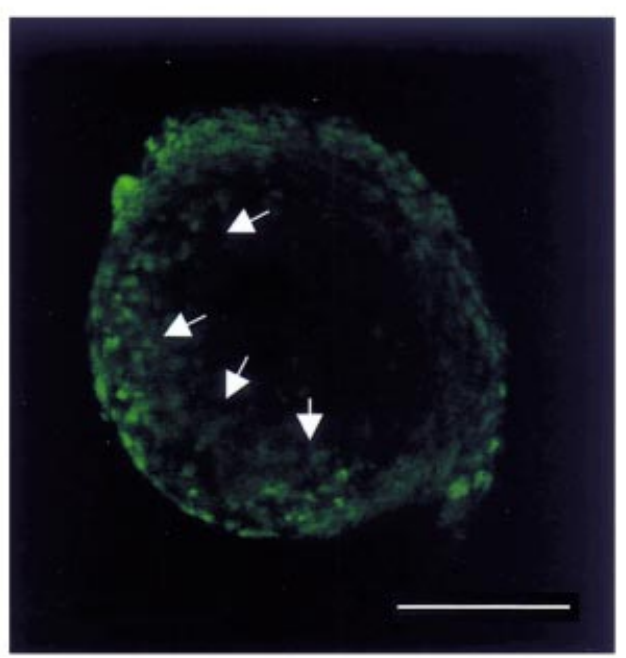

Fig. 3. (a) Ascorbic acid-treated bovine follicles on day 12 of culture. (i) Follicle stained with propidium iodide (red); (ii) theca cells undergoing cell death labelled with fluorescein dUTP (green). (b) Control follicle on day 12 of culture. (i) Follicle stained with propidium iodide (red); (ii) mural granulosa cells and theca cells undergoing cell death labelled with fluorescein dUTP (green). Arrows indicate cell death, as detected by TUNEL. Scale bars represent $100 \mu \mathrm{m}$. 


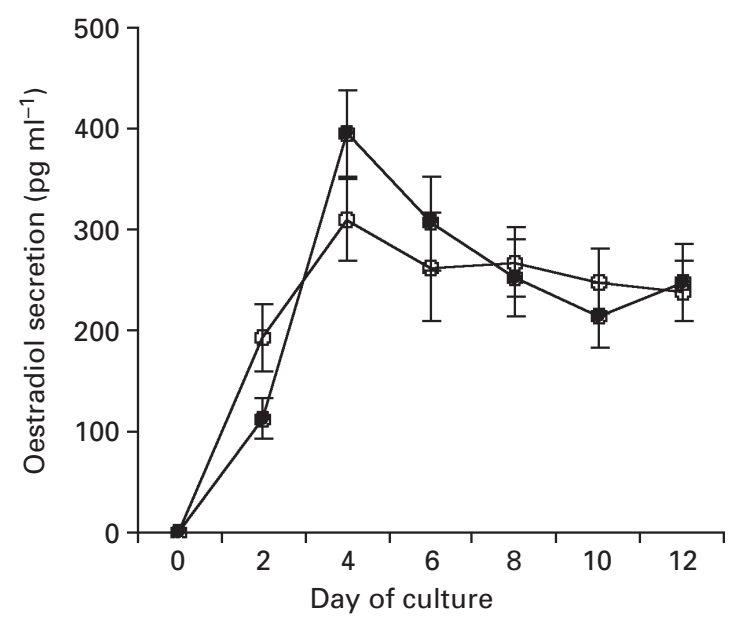

Fig. 4. Oestradiol secretion by bovine follicles in the presence $(\bigcirc ; n=42)$ or absence $(0 ; n=45)$ of ascorbic acid. Values are mean \pm SEM. $n$ represents the number of follicles in each treatment group.

basement membrane integrity) during the 12 days of culture. For follicles cultured for 10 days, there was a significant correlation only in the absence of ascorbic acid $(P<0.05)$. From day 8 of culture onwards, significantly $(P<0.05)$ more ascorbic acid-treated follicles remained intact in the absence of serum compared with control follicles and follicles treated with serum from day 0 (Fig. 2). By day 10 , follicles cultured with medium containing serum from day 0 had a significantly greater loss of basement membrane integrity than follicles in all other treatment groups $(P<0.05)$. By day 12 , a higher proportion of follicles cultured with serum-free medium supplemented with ascorbic acid remained intact than in any other group $(P<0.05)$.

\section{Detection of cell death by TUNEL}

Freshly isolated follicles (day $0 ; n=8$ ) and follicles cultured for 12 days (control, $n=9$; ascorbic acid, $n=9$; serum added day $6, n=8$; ascorbic acid with serum added day $6, n=9$ ) were stained by TUNEL for the occurrence of cell death. Results were obtained from two TUNEL experiments, using follicles from at least three cultures carried out under identical conditions. The largest cross-section of the follicle or the section containing the oocyte germinal vesicle was analysed using confocal microscopy and image analysis. The occurrence of cell death (expressed as a percentage) in the granulosa compartment was significantly different among all treatment groups $(P<0.05)$ (Table 1$)$. There was no granulosa cell death in freshly isolated follicles or in follicles cultured with ascorbic acid (with or without serum). There was significantly $(P<0.001)$ more granulosa cell death in follicles cultured in control medium and in those cultured in control medium containing serum than in day 0 follicles or in follicles treated with ascorbic acid alone. Follicles treated with serum had less cell death in granulosa cells when ascorbic acid was also present

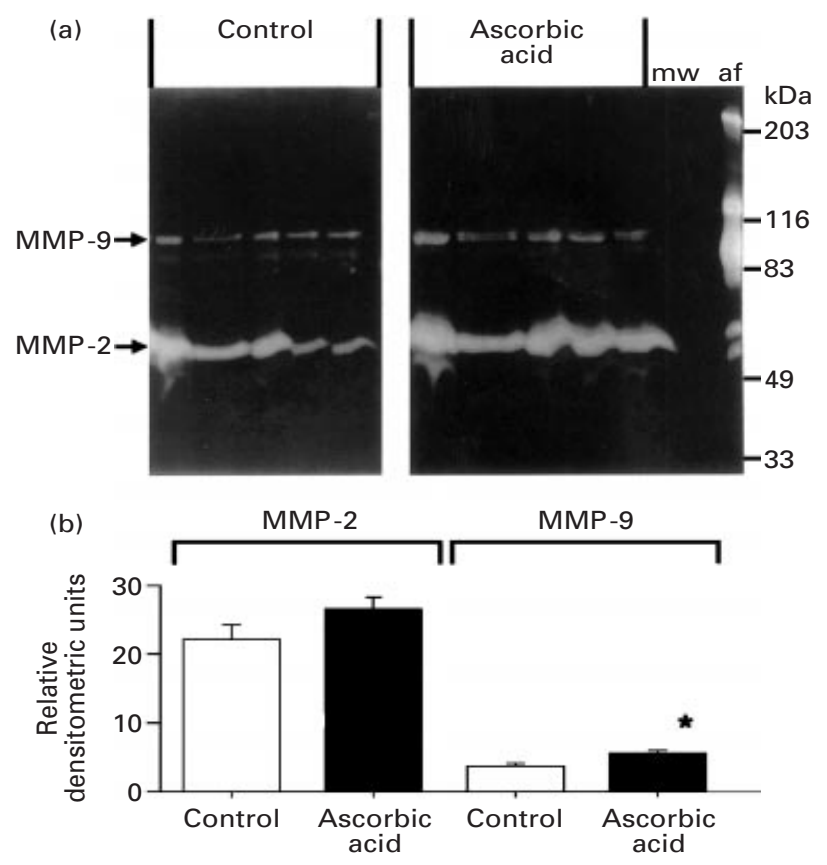

Fig. 5. (a) Representative gelatin zymography gels showing gelatinase activities in conditioned medium collected from bovine follicles maintained in culture for 8 days, either untreated (control) or treated with ascorbic acid. Gelatinase activities corresponding to the latent forms of matrix metalloproteinases (MMP) MMP-2 and MMP-9 are indicated. A sample of human amniotic fluid (af) collected at term was used as a positive control. Molecular weight markers (mw) are as indicated (kDa). (b) Densitometric analysis (expressed as relative densitometric units; mean $\pm \mathrm{SEM} ; n=12$ ) of the gelatinase activities of the latent forms of MMP-2 and MMP-9 in conditioned medium collected from bovine follicles after 8 days in culture, with no treatment (control) or treated with ascorbic acid. *Significantly $(P<0.05)$ greater MMP-9 activity than controls.

$(P<0.001)$. In addition, follicles cultured with ascorbic acid displayed a significantly $(P<0.01)$ lower incidence of theca cell death than controls (Table 1). Examples of a follicle with healthy (as assessed by the absence of TUNEL labelling) granulosa cells and a follicle undergoing granulosa cell death are shown (Fig. 3).

\section{Oestradiol secretion}

During the 12 day culture period, there was significant $(P<0.01)$ oestradiol secretion by follicles in serum-free medium in the presence and absence of ascorbic acid (Fig. 4). No significant differences in oestradiol secretion were observed between ascorbic acid and control groups.

\section{MMP-2 and MMP-9 secretion}

Ascorbic acid-treated $(n=12)$ and control medium $(n=12)$ from day 8 of culture were analysed for MMP activity. MMP-2 (72 kDa) and MMP-9 (92 kDa) were detected in all samples. Densitometric analysis showed that latent MMP-9 activity was significantly higher in conditioned 
medium from ascorbic acid-treated follicles $(P<0.05)$. The densitometric readings, taken within the range of linear sensitivity of the zymogram gel, represent a 1.5 -fold increase (3748-5784 densitometric units) in enzyme activity. An example of a zymogram demonstrating MMP-2 and MMP-9 activity is shown (Fig. 5).

\section{Discussion}

The results presented here demonstrate successful growth and differentiation of bovine preantral follicles cultured for 12 days in a serum-free medium. In addition, ascorbic acid was found to maintain follicle integrity in the absence of serum throughout the culture period, reduce the incidence of cell death, and may participate in the regulation of remodelling the extracellular matrix.

Ideally, a long-term culture system would be serum-free to allow the determination of optimal conditions for follicle development. Replacement of serum with ascorbic acid in this culture system did not significantly increase follicle growth, but it did allow the follicles to maintain their normal morphology throughout the culture period. An increased rate of follicle growth was shown to correlate with a significant decrease in follicle integrity during the 12 day culture period. The presence of serum in the culture medium may have accelerated follicle development at a rate that could not be sustained, which led to follicle rupture. In addition, there was substantial theca cell loss from follicles in serum-treated groups (results not shown). The effect of serum in promoting migration of theca cells to the substrate is in agreement with the study by Ralph (1996), who reported loss of theca cells from bovine preantral follicles cultured in the presence of serum. Therefore, the increase in granulosa cell death in serum-treated follicles reported here may be due to decreased cell adhesion, which increases the susceptibility of granulosa cells and other cell types to apoptosis (Peluso, 1997; Sakai et al., 2000).

Little is known about the regulators of follicle growth during the gonadotrophin-independent stages of development. Early evidence for the role of ascorbic acid has come from the use of scorbutic guinea-pigs (Kramer et al., 1933); these guinea-pigs are infertile due to ascorbic acid deficiency and demonstrate degeneration in the follicle wall that is consistent with loss of basement membrane integrity (Kramer et al., 1933). Although little is known about the role of ascorbic acid in facilitation of follicle expansion in the growth phase, depletion of ascorbic acid is associated with structural involution in the corpus luteum in conjunction with increased activity of matrix-degrading enzymes (Endo et al., 1993). Ascorbic acid, acting as an antioxidant, has been implicated in collagen biosynthesis (Pinnell, 1985), which is essential for basement membrane construction during follicle growth.

Regulated degradation of the extracellular matrix may provide an important mechanism for regulation of growth factor availability and activity during follicle development
(McIntush and Smith, 1998). With respect to the preantral and early antral stages of follicular development, the contribution of the various MMPs and associated regulators to follicular remodelling is not well understood. McCaffery et al. (2000) demonstrated that secretion of MMP-9 and TIMP-1 and -2 from bovine preantral follicles during culture are markers of follicle health at day 6 . In the present study, MMP-2 and -9 were secreted by follicles on day 8 of culture in the presence and absence of ascorbic acid. This finding indicates that the majority of follicles were able to proceed to this stage and remain healthy in basic serum-free culture medium. However, from day 8 onwards there was an increased loss of basement membrane integrity in the absence of ascorbic acid, and by day 12 there was an increase in cell death in these groups. Results from the present study are in agreement with other studies in vitro (Rose et al., 1999; Murray et al., 2001), which have demonstrated promotion of follicle integrity and survival by ascorbic acid in cultured mouse follicles. The study by Murray et al. (2001) also reported an increase in MMP and TIMP activity in the presence of ascorbic acid. The zymography results presented in the current study emphasise the usefulness of MMP detection as a means of monitoring follicle health throughout culture. In addition, it was shown that ascorbic acid may increase MMP-9 activity, which implies a role for ascorbic acid in the regulation of extracellular matrix turnover and the maintenance of follicle health during long-term culture. In another study, the importance of maintaining healthy theca cells and their connections with the granulosa layers in bovine follicle culture has been emphasized, and a role for these types of cell in basement membrane remodelling during the early stages of folliculogenesis was supported (McCaffery et al., 2000). However, other studies have reported follicle rupture or loss of theca cells from bovine preantral follicles during culture (Ralph et al., 1995; Gutierrez et al., 2000). The fact that ascorbic acid has been identified to significantly reduce theca cell death in vitro in the present study may help to overcome these problems and facilitate normal folliculogenesis in vitro.

It is important to define conditions that are conducive to somatic cell survival to maintain health and normal development of the oocyte in vitro. The role of ascorbic acid in the neutralization of free radical species has been studied extensively. As well as having relevance to follicle remodelling, the action of ascorbic acid affects the process of follicular cell death. Tilly and Tilly (1995) reported that accumulation of free radical species in tropic factordeprived follicles is involved in triggering granulosa cell apoptosis. These authors also found that FSH suppressed apoptosis in cultured antral follicles of rats, and that this effect was mimicked by antioxidants including ascorbic acid. In the culture system used in the present study, granulosa and theca cells of follicles treated with ascorbic acid had a significantly lower incidence of cell death (as analysed by TUNEL) compared with control follicles in serum-free medium. When serum was added to follicles on 
day 6 of culture, there was significantly more granulosa cell death by day 12 of culture than in ascorbic acid-treated follicles. However, this effect was not apparent when serum was added in conjunction with ascorbic acid. As more follicles were found to lose basement membrane integrity in the presence of serum, any deleterious effects may be due to inappropriate stimulation of follicles by serum during the early stages of development.

Ascorbic acid had no significant effect on the production of oestradiol by follicles during the culture period. This finding is in agreement with a study using cultured mouse follicles (Murray et al., 2001). Ascorbic acid is thought to play a similar role in steroidogenesis in the ovary as in the adrenal gland, in which high concentrations of ascorbic acid inhibit steroid biosynthesis through inhibition of hydroxylation systems (Kitabchi, 1967). However, the precise mechanism through which this is effected is not well understood. Since ascorbic acid uptake in granulosa cells is positively regulated by $\mathrm{FSH}$ and IGF-I in a synergistic manner similar to the control of granulosa cell differentiation (Giudice, 1992; Behrman et al., 1996), ascorbic acid may play an important part in expansion, survival and steroidogenesis in the later stages of folliculogenesis and during the establishment of dominance.

In conclusion, it has been shown that ascorbic acid improves the quality of bovine follicles and their survival in a serum-free culture system. In addition, a role for ascorbic acid in the regulation of follicle remodelling by influencing MMP production was identified. Ascorbic acid had no effect on oestradiol production or follicle growth in this study. Further investigations are required to determine whether the effect of ascorbic acid on follicle health leads to improvement of oocyte quality in vitro. A technique for obtaining a source of homogeneous mature oocytes from bovine ovaries would provide a model for in vitro maturation and fertilization systems for human oocytes, as well as facilitating investigations into postovulatory and embryonic development.

The authors thank D. Thomas for advice on the statistical analysis, J. Binnie for help with the histological preparation and L. Sharp for assistance with the confocal microscopy. This study was supported by the Ministry of Agriculture, Fisheries and Food.

\section{References}

Abir R, Franks S, Mobberley MA, Moore PA, Margara RA and Winston RM (1997) Mechanical isolation and in vitro growth of preantral and small antral human follicles Fertility and Sterility 68 682-688

Behrman HR, Preston SL, Aten RF, Rinaudo P and Zreik TG (1996) Hormone induction of ascorbic acid transport in immature granulosa cells Endocrinology 10 4316-4321

Cecconi S, Barboni B, Coccia M and Mattioli M (1999) In vitro development of sheep preantral follicles Biology of Reproduction $\mathbf{6 0}$ 594-601

Cortvrindt R, Smitz J and Van Steirteghem AC (1996) In vitro maturation, fertilisation and embryo development of immature oocytes from early preantral follicles from prepubertal mice in a simplified culture system Human Reproduction 11 2656-2666

Deane HW (1952) Histochemical observation on the ovary and oviduct of the albino rat during the estrous cycle American Journal of Anatomy $\mathbf{9 1}$ 363-413

Endo T, Aten RF, Wang F and Behrman HR (1993) Coordinate induction and activation of metalloproteinase and ascorbate depletion in structural luteolysis Endocrinology 133 690-698

Eppig J and Schroeder AC (1989) Capacity of mouse oocytes from preantral follicles to undergo embryogenesis and development to live young after growth, maturation and fertilisation in vitro. Biology of Reproduction 41 268-276

Figueiredo JR, Hulshof SCJ, Thiry M, Van den Hurk R, Bevers MM, Nusgens B and Beckers JF (1995) Extracellular matrix proteins and basement membrane: identification in bovine ovaries and significance for the attachment of cultured preantral follicles Theriogenology 43 845-858

Giudice LC (1992) Insulin-like growth factors and ovarian development Endocrine Reviews 13 641-669

Gutierrez CG, Ralph JH, Telfer EE, Wilmut I and Webb R (2000) Growth and antrum formation of bovine preantral follicles in long term culture in vitro. Biology of Reproduction 62 1322-1328

Himeno N, Kawamura N, Okamura H, Mori T, Fukomoto $M$ and Midorikawa O (1984) Collagen synthetic activity in rabbit ovary during ovulation and its blockage by indomethacin Acta Obstetrica and Gynaecologica Japonica 36 1930-1934

Hirao Y, Nagai T, Kubo M, Miyano T, Miyake M and Kato S (1994) In vitro growth and maturation in pig oocytes Journal of Reproduction and Fertility $100333-339$

Hoch-Ligeti C and Bourne GH (1948) Changes in the concentration and histological distribution of ascorbic acid in ovaries, adrenals and livers of rats during oestrous cycles British Journal of Pathology 29 400-407

Hulmes DJS (1992) The collagen superfamily: diverse structures and assemblies Essays in Biochemistry 27 49-67

Hulshof SCJ, Figueiredo JR, Beckers JF, Bevers MM, Van der Donk JA and Van den Hurk R (1995) Effects of recombinant FSH, $17 \beta$-oestradiol and their combination on bovine preantral follicles in vitro. Theriogenology $44217-226$

Kitabchi AE (1967) Ascorbic acid in steroidogenesis Nature 215 1385-1386

Kramer MM, Harman MT and Brill AK (1933) Disturbances of reproduction and ovarian changes in the guinea-pig in relation to vitamin $C$ deficiency American Journal of Physiology 106 611-622

Luck MR and Zhao Y (1993) Identification and measurement of collagen in the bovine corpus luteum and its relationship with ascorbic acid and tissue development Journal of Reproduction and Fertility 99 647-652

Luck MR, Jeyaseelan I and Scholes RA (1995) Ascorbic acid and fertility Biology of Reproduction 52 262-266

McCaffery FH, Leask R, Riley SC and Telfer EE (2000) Culture of bovine preantral follicles in a serum-free system: markers for assessment of growth and development Biology of Reproduction 63 267-273

McIntush EW and Smith MF (1998) Matrix metalloproteinases and tissue inhibitors of metalloproteinases in ovarian function Reviews of Reproduction 3 23-30

Murray AA, Molinek MD, Baker SJ, Kojima FN, Smith MF, Hillier SG and Spears N (2001) Ascorbic acid promotes follicle integrity and survival in intact murine ovarian follicles in vitro. Reproduction 121 89-96

Padh H (1991) Vitamin C: newer insights into its biochemical functions Nutrition Reviews 49 65-70

Peluso JJ (1997) Putative mechanism through which N-cadherin-mediated cell contact maintains calcium homeostasis and thereby prevents ovarian cells from undergoing apoptosis Biochemical Pharmacology 54 847-853

Pfeffer F, Casenueva E, Kamar J, Guerra A, Perichart $O$ and Vadillo-Ortega F (1998) Modulation of 72-kilodalton type IV collagenase (matrix metalloproteinase-2) by ascorbic acid in cultured human amnionderived cells Biology of Reproduction 59 326-329

Pinnell SR (1985) Regulation of collagen synthesis by ascorbic acid: a review Yale Journal of Biology and Medicine 58 553-559

Ralph JH (1996) Factors Affecting Follicle and Oocyte Development in Cattle PhD Thesis, University of Edinburgh

Ralph JH, Telfer EE and Wilmut I (1995) In vitro growth of bovine preantral follicles and the influence of FSH on follicular and oocyte diameters Journal of Reproduction and Fertility Abstract Series 15 Abstract 12 
Riley SC, Leask R, Chard T, Wathen NC, Calder A and Howe DC (1999) Secretion of matrix metalloproteinase-2, matrix metalloproteinase- 9 and tissue inhibitors of metallproteinases into the intrauterine compartments during early pregnancy Molecular Human Reproduction 5 376-381

Rose UM, Hanssen RG and Kloosterboer HJ (1999) Development and characterization of an in vitro ovulation model using mouse ovarian follicles Biology of Reproduction 61 503-511

Roy SK and Greenwald GS (1989) Hormonal requirements for the growth and differentiation of hamster preantral follicles in long term culture Journal of Reproduction and Fertility 87 103-114

Saha S, Shimizu M, Geshi M and Izaike Y (2000) In vitro culture of bovine preantral follicles Animal Reproduction Science 63 27-39

Sakai H, Kobayashi Y, Sakai E, Shibata M and Kato Y (2000) Cell adhesion is a prerequisite for osteoclast survival Biochemical and Biophysical Research Communications 270 550-556

Sanyal S and Datta S (1979) Effect of ascorbic acid in in vitro rat adrenal and ovarian steroidogenesis Indian Journal of Experimental Biology 17 $86-88$

Spears N, Boland NI, Murray AA and Gosden RG (1994) Mouse oocytes derived from in vitro grown primary ovarian follicles are fertile Biology of Reproduction 48 798-806

Telfer EE, Binnie JP, McCaffery F and Campbell BK (2000) Development of immature follicles from porcine and bovine ovaries Molecular and Cellular Endocrinology 163 117-123

Tilly JL and Tilly KI (1995) Inhibitors of oxidative stress mimic the ability of follicle-stimulating hormone to suppress apoptosis in cultured rat ovarian follicles Endocrinology 136 242-252

Torrance C, Telfer EE and Gosden RG (1989) Quantitative study of the development of isolated mouse preantral follicles in collagen gel culture Journal of Reproduction and Fertility 87 367-374

Tsuji M, Ito Y, Terada N and Mori H (1989) Ovarian aromatase action in scorbutic mutant rats unable to synthesise ascorbic acid Acta Endocrinologica (Copenh) 121 595-602

Van den Hurk R, Abir R, Telfer EE and Bevers MM (2000) Primate and bovine immature oocytes and follicles as sources of fertilizable oocytes Human Reproduction Update 6 457-474

Webb R, Baxter G, McBride D, Nordblom CD and Shaw MPK (1985) The measurement of testosterone and oestradiol-17 $\beta$ using iodinated tracers and incorporating an affinity chromatography extraction procedure Journal of Steroid Biochemistry 23 1043-1051

Wise T (1987) Biochemical analysis of bovine follicular fluid: albumin, total protein, lysosomal enzymes, ions, steroids and ascorbic acid content in relation to follicular size, rank, atresia classification and day of estrous cycle Journal of Animal Science $\mathbf{6 4} 1153-1169$

Wright CS, Hovatta O, Margara R, Trew G, Winston RM, Franks S and Hardy K (1999) Effects of follicle stimulating hormone and serum substitution on the in vitro growth of human ovarian follicles Human Reproduction 14 1555-1562

Wu J, Emery BR and Carrell DT (2001) In vitro growth, maturation, fertilisation and embryonic development of oocytes from porcine preantral follicles Biology of Reproduction 64 375-381

Received 10 January 2001.

First decision 21 March 2001

Accepted 16 May 2001. 